\title{
O ENSINO DE QUÍMICA E OS 40 ANOS DA SBQ: O DESAFIO DO CRESCIMENTO E OS NOVOS HORIZONTES
}

\author{
Márlon Herbert Flora Barbosa Soares ${ }^{\mathrm{a}, *}$, Nyuara Araújo da Silva Mesquita ${ }^{\mathrm{a}}$ e Daisy de Brito Rezende \\ anstituto de Química, Universidade Federal de Goiás, 74001-970 Goiânia - GO, Brasil

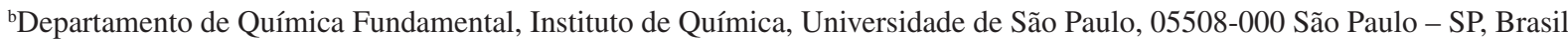

Recebido em 02/04/2017; aceito em 08/05/2017

\begin{abstract}
CHEMISTRY TEACHING AND THE SBQ 40 YEARS: THE GROWTH CHALLENGE AND THE NEW HORIZONS. In this work, we aim to draw a panorama of the chemistry teaching area and its relation with the teaching division in SBQ 40 years. We start from the analysis of the Chemistry Teaching National Meetings in the last 15 years in comparison with those occurred in the 80's and 90's. Then, we present the growth of the chemistry teaching regional meetings and their capacity to congregate researchers and students in a decentralized way, important to the inclusion of new chemical educators. We discuss the scientific journals in the area considering the research on various themes. Finally, we analyze the growth of chemistry degree courses in Brazil and the number of researchers in the area, as well as the main themes explored by the research field of Chemistry Teaching in Brazil.
\end{abstract}

Keywords: Chemistry Teaching, SBQ 40 years; teaching Division.

\section{INTRODUÇÃO}

A divisão de Ensino de Química (DED) foi uma das primeiras divisões científicas da Sociedade Brasileira de Química. Foi criada em Julho de 1988, durante a XI Reunião Anual da Sociedade Brasileira de Química, realizada na cidade de São Paulo - SP, entre os dias 10 e 16 de Julho de 1988 e teve como sua primeira diretora a Professora Roseli Pacheco Schnetzler, à época, na Faculdade de Educação da UNICAMP, acompanhada de sua vice-diretora, a professora Maria Eunice Ribeiro Marcondes, do Instituto de Química da Universidade de São Paulo.

Segundo Schnetzler ${ }^{1}$, a criação e constituição da Divisão de Ensino de Química (DED) foi um dos grandes marcos no desenvolvimento de pesquisas em Ensino de Química no Brasil porque apoiou a promoção de eventos regionais e nacionais sobre Ensino de Química e criou a revista Química Nova na Escola. Outro marco importante é o crescimento do número de mestres e doutores na área de Ensino de Química, que redundou em mais projetos de pesquisa na área e em livros didáticos e paradidáticos escritos com base nos resultados obtidos das pesquisas desenvolvidas pelos diferentes grupos que foram se estabelecendo nas universidades em todo o País.

Não faremos neste artigo, uma repetição das ideias já apresentadas em um artigo com características de estado da arte sobre a área de Ensino de Química, ${ }^{1}$ publicado em um número comemorativo de Química Nova, aos 25 anos da SBQ. Pretendemos, nesse artigo, complementar as ideias ali contidas, debatendo e apresentando o que a Divisão de Ensino fez nos últimos quinze anos para a área de Ensino de Química, considerando as perspectivas apontadas naquele trabalho de 2002, além, é claro, de apontar possíveis mudanças e as novas perspectivas que nos aguardam.

Adiantamos que algumas mudanças são visíveis, no entanto, os possíveis problemas e perspectivas que foram apontados em 2002 continuam da mesma forma e merecem ser o mote para as lutas dos próximos anos no âmbito da Divisão de Ensino da Sociedade Brasileira de Química. Dessa forma, apresentaremos aspectos relevantes dos principais espaços em que se estruturaram e se estruturam os caminhos da área de Ensino de Química no Brasil, hoje. Dentre esses espaços, temos os Encontros Nacionais de Ensino de Química,

*e-mail: marlon@ufg.br vários Encontros Regionais de Ensino de Química, as revistas que publicam os resultados das investigações e o aumento do número de pesquisadores na área.

\section{OS ENCONTROS NACIONAIS EM ENSINO DE QUIMICA}

A partir de 2002, o Encontro Nacional de Ensino de Química (ENEQ) continuou ocorrendo bienalmente. A Tabela 1 sumaria alguns dados sobre os ENEQs. Esses eventos foram, de alguma maneira, apoiados ou chancelados pela DED, seja no que se refere a passagens de convidados ou, ainda, apoio logístico. Tais apoios foram diminuindo ao longo do tempo devido a não mais existirem projetos específicos da Divisão para a organização de encontros científicos, em decorrência principalmente do acirramento das dificuldades de financiamento para a Ciência, que vêm se agravando ao longo dos anos.

Nota-se um aumento considerável no número de inscritos e de trabalhos apresentados, sejam resumos ou trabalhos completos, de 2002 até 2016. Entre 1982, data do primeiro ENEQ, até 2000, quando da décima edição, tivemos uma média de 400 inscritos, com um ápice de quase 800 presentes no ano 2000 em Porto Alegre. Nos últimos 15 anos, esse média subiu consideravelmente para cerca de 1300 presentes, ou seja, um aumento médio de mais de $200 \%$. O número de trabalhos seguiu a mesma lógica de crescimento. Até o ano 2000 (X ENEQ) tivemos uma média de 100 a 150 trabalhos, todos na forma de resumos. Entre 2002 e 2016, a média foi de cerca de 400 resumos e 250 trabalhos completos. Uma média geral próxima a 650 trabalhos científicos, ou seja, um aumento de mais de $400 \%$. É evidente a diferença de trabalhos entre esses dois intervalos. É importante salientar que a partir de 2006, o ENEQ passa a aceitar os trabalhos completos, de no mínimo, 10 páginas.

Nas edições anteriores sempre existiram as sessões coordenadas a partir da seleção dos resumos submetidos. Na décima terceira edição, as sessões coordenadas foram selecionadas a partir dos trabalhos completos e também por áreas específicas, que foram utilizadas até o último ENEQ, com pequenas variações, a saber: Ciência, Tecnologia e Sociedade; Currículo e Avaliação; Educação Ambiental; Educação em Espaços Não Formais e Divulgação Científica; Ensino e Aprendizagem; Experimentação no Ensino; Formação de Professores; História, Filosofia e Sociologia da 
Tabela 1. Encontros Nacionais de Ensino de Química a partir do ano 2002. Número de Participantes e Trabalhos

\begin{tabular}{|c|c|c|c|c|c|c|}
\hline ANO & LOCAL & Edição & Participantes $^{\mathrm{a}}$ & Trabalhos Completos & Resumos & Total $^{\mathrm{b}}$ \\
\hline 2002 & Recife - PE (UFRPE) & XI & 900 & - & 181 & 181 \\
\hline 2004 & Goiânia - GO (UFG) & XII & 1300 & - & 267 & 267 \\
\hline 2006 & Campinas - SP (UNICAMP) & XIII & 1000 & 85 & 250 & 335 \\
\hline 2008 & Curitiba - PR (UFPR) & XIV & 1200 & 200 & 262 & 462 \\
\hline 2010 & Brasília - DF (UnB) & $X V$ & 1700 & 212 & 355 & 567 \\
\hline 2012 & Salvador - BA (UFBA) & XVI & 2000 & 324 & 565 & 889 \\
\hline 2014 & Ouro Preto - MG (UFOP) & XVII & 2000 & $420^{\mathrm{a}}$ & $600^{\mathrm{a}}$ & $1020^{\mathrm{a}}$ \\
\hline 2016 & Florianópolis - SC (UFSC) & XVIII & 2300 & 771 & 823 & 1594 \\
\hline
\end{tabular}

${ }^{a}$ Números aproximados. ${ }^{b}$ ão foram computadas as submissões ao Momadiq.

Ciência; Inclusão e Políticas Educacionais; Linguagem e Cognição; Materiais Didáticos e Tecnologias da Informação e Comunicação. Esse aumento no número de trabalhos, que tem sido constante e gradativo, reflete o crescimento da área de pesquisa em Ensino de Química, no Brasil. No entanto, apesar do fato ser positivo, ele acaba por causar outro tipo de problema, que é a superlotação e a dificuldade para que sejam alocadas as apresentações da grande quantidade de trabalhos submetidos e aceitos. Logo, esse aspecto passa a ser uma preocupação para os próximos anos no que se refere à logística de um evento que só tende a crescer.

Por outro lado, salientamos que esse aumento considerável não veio acompanhado de melhoria na qualidade. Se houve o aumento do número de trabalhos de qualidade, ainda temos trabalhos aprovados que não consideram adequadamente os estudos da área já publicados e, às vezes, são meras repetições ou, ainda, carecem de referenciais teóricos atuais. Há dificuldades, também, no que se refere a pareceristas para essa grande quantidade de trabalhos. O número de pesquisadores com formação específica na área de Ensino de Química ainda é pequeno para atender à demanda de trabalhos submetidos nas últimas edições tanto da RASBQ quanto dos ENEQs.

Não podemos deixar de mencionar que a DED se mostrou como um espaço agregador dos pesquisadores da área desde sua criação, mas que o movimento de discussão destes pesquisadores também se estruturou em outros espaços como os Encontros Nacionais de Ensino de Química (ENEQ) e os encontros regionais (ECODEQ, EDEQ, dentre outros). Entendemos que, nesses diversos espaços de reuniões e debates de professores, licenciandos e pesquisadores, estabeleceu-se a interlocução entre diferentes perspectivas investigativas que sustentam e direcionam os caminhos do ensino e da pesquisa na área de pesquisa sobre Ensino de Química no País. A partir de tal interlocução, organizou-se a comunidade de educadores químicos no Brasil.

A partir de 2016, a comunidade decidiu, conjuntamente, haver necessidade de que os ENEQs fossem realizados em cada uma das cinco regiões geográficas brasileiras, em um sistema de rodízio. Essa decisão reflete a tentativa de congregar mais pesquisadores, pela descentralização dos encontros, ao invés de centralizar as ações em uma ou duas das regiões em que já se concentra a maior parte do universo de pesquisadores em Ensino de Química. Essa ação pode contribuir para que o número de pesquisadores sobre o ensino de química seja cada vez maior e distribuído mais equitativamente pelo território nacional. A participação dos professores atuantes na escola básica e as possíveis intervenções nessas escolas, associadas à ocorrência do encontro, é facilitada, favorecendo que os resultados de nossas pesquisas sejam divulgados mais amplamente para os profissionais da educação e seus alunos.
Nesse aspecto, foi bastante positiva a decisão da comunidade de pesquisadores em ensino de Química de realizar o ENEQ de 2018 em Manaus (AM). Isso se torna importante na medida em que será a primeira vez que esse encontro se realizará na região Norte, o que advém da necessidade da comunidade de contribuir para agregar os educadores em Química de todas as regiões do País. Nesse mesmo sentido, o ENEQ tem buscado não se restringir à apresentação estrita de trabalhos de pesquisa no campo do Ensino de Química. A inserção, a partir de 2008, das Mostra de Material Didático como uma nova seção no âmbito do ENEQ do evento também foi uma importante iniciativa da comunidade de pesquisadores em Ensino de Química no sentido de agregar outras produções ao ENEQ, que já contava com uma seção de Relatos de Sala de Aula. Esse espaço possibilitou aos participantes a apresentação de materiais de caráter inovador que contemplam desde livros, softwares, CDs, sites, jogos, entre vários outros. Além de democratizar a participação de educadores em Química no evento, ambas as iniciativas podem apontar caminhos para a diversificação da pesquisa, que sinalizam novas perspectivas de estudos associados à produção de materiais que se voltem a novas propostas metodológicas para as abordagens de conceitos no cenário da sala de aula.

\section{As sessões coordenadas da Divisão de Ensino na SBQ}

Também com alcance nacional, durante as reuniões anuais da SBQ, a Divisão de Ensino tem espaço para a publicação e apresentação dos seus trabalhos. Há uma sessão de painéis com todos os resumos submetidos e destes, selecionam-se alguns trabalhos pelo corpo de árbitros para apresentação oral na forma de sessão coordenada. No intervalo de 1978-2001, saímos de 5 trabalhos na primeira reunião anual, para 108. ${ }^{1} \mathrm{O}$ crescimento foi sempre constante, e em 2013, a partir da 36 ${ }^{\text {a }}$ RA, ao passarmos de 150 trabalhos, a Divisão de Ensino foi uma das divisões que passaram a contar com duas sessões coordenadas nas reuniões anuais da SBQ, apesar de um decréscimo para cerca de 115 trabalhos em média nos últimos 3 anos.

Além dos ENEQs, outro locus de discussão entre pesquisadores, professores e estudantes das Licenciaturas em Química de diferentes regiões do País são os eventos regionais. Esses espaços têm-se revelado como espaços muito importantes, pois possibilitam a ampliação e democratização das discussões por alcançarem um universo mais diversificado de pessoas. Isso ocorre porque facilitam a inserção das redes estaduais e municipais de Educação em debates que envolvem a formação continuada de professores e o estabelecimento de parcerias entre Instituições de Ensino Superior (IES) e as escolas da Educação Básica.

Há outros encontros nacionais nos quais são apresentados trabalhos na área de ensino de química, no entanto sem ligação direta com 
a SBQ, tais como os ENPECs (Encontro Nacional de Pesquisa em Educação em Ciências), os CBQs (Congresso Brasileiro de Química) e os SIMPEQUIs (Simpósio Brasileiro de Educação Química).

\section{ENCONTROS REGIONAIS DE ENSINO DE QUÍMICA}

O mais tradicional encontro regional sobre Ensino de Química que, pela quantidade de participantes e alcance, tem uma característica quase nacional é o EDEQ, Encontro de Debates em Ensino de Química, que acontece no Estado do Rio Grande do Sul, em sistema de rodízio entre as universidades gaúchas. O tema central do $36^{\circ}$ EDEQ foi "Novas e antigas práticas: encontrando-se com a comunidade e sua criatividade em Educação Química" e ocorreu de 14 a 15 de outubro de 2016, na cidade de Pelotas (RS), sob os auspícios da UFPel. Abordou, dentre outros temas, o movimento de legitimação do campo de pesquisa do Ensino de Química, discussão importante considerando-se o atual momento político pelo qual passa o País em que as licenciaturas, em geral, têm discutido o processo de desmantelamento da educação nacional em seus diversos níveis de ensino. Reafirmarmos a importância de nosso posicionamento político e epistemológico como área de ensino e pesquisa que influencia fortemente a formação de alunos e professores tanto da Educação Básica como nas IES. A responsabilidade dos pesquisadores, docentes nas IES, é imensa, no sentido de contribuir decisivamente para o fortalecimento e a qualificação desse campo de estudos, que deveria conduzir a modificações na prática nas salas de aula de todos os níveis de ensino. Em 2017, realizará sua 37a edição. Uma de suas características importantes é que este evento acontece desde 1980, ou seja, sua realização antecede a criação do ENEQ e o inspirou. ${ }^{1}$

Já a partir de 2002, podemos destacar o crescimento de alguns eventos regionais. Na Bahia, destacamos o Encontro de Educação em Química da Bahia que, em 2013, realizou seu XI evento. O EDUQUI foi criado em 1989 e tem uma média de 300 participantes em seus eventos. Para Silva et $a l .^{2}$, a partir do ano 2000, o EDUQUI representou uma virada política, já que, na década anterior, havia ocorrido uma virada epistemológica. De acordo com os autores, o Ensino de Química começou a ter reconhecimento na Bahia, alterando a convicção de que a pesquisa em ensino deveria ser realizada apenas nas Faculdades de Educação, abrindo espaço nos Instituto e Departamentos de Química das universidades baianas.

Houve, também, no Estado de São Paulo, a criação do Evento em Ensino de Química (EVEQ) e do Encontro Paulista de Pesquisa em Ensino de Química (EPPEQ). No estado, também há o SIMPEQ, que é o Simpósio de Profissionais do Ensino de Química, que acontece no Instituto de Química da UNICAMP, desde 2001, congregando membros da universidade e professores do Ensino Médio.

O EVEQ foi criado em 2003, por iniciativa de estudantes de graduação do Instituto de Química de Araraquara, ${ }^{3}$ da UNESP, envolvidos com atividades de extensão. Tem como objetivos principais a reflexão sobre trabalhos referentes ao ensino de Química e sua divulgação, visando aprimorar a formação dos licenciandos do curso; em 2017, ocorrerá sua XV edição. Conta com uma média de 150 participantes e sempre ocorre no Instituto de Química da UNESP, em Araraquara. O número médio de trabalhos científicos, por evento, é de aproximadamente 50, incluindo resumos e resumos expandidos. ${ }^{3} \mathrm{O}$ EPPEQ foi concebido, no início dos anos 2000, no âmbito do Grupo de Trabalho Químicas Integradas (G6), do qual faziam parte representantes dos seis cursos de graduação em Química, então oferecidos por Universidades públicas do Estado de São Paulo (IQ-USP, IQSC-USP, FFCLRP-USP, IQ-Unicamp, IQ-Araraquara-UNESP e DQ-UFSCar), além da Faculdade de Educação da Unicamp. Sua primeira edição ocorreu em 2004, na UNICAMP, em conjunto com o IV SIMPEQ e contou com a participação de 120 pessoas. O segundo EPPEQ deu-se no campus do Instituto de Química de Araraquara, em conjunto com o EVEQ e o III Fórum de Professores do Ensino Médio, chegando a 400 inscrições. O terceiro EPPEQ foi sediado na UNICAMP, em conjunto com o ENEQ, o que elevou o número de participantes para 1200. Decidiu-se que o IV EPPEQ seria organizado independentemente de outros congressos, porque esse seria um passo importante para a consecução de seus objetivos de propiciar o estabelecimento de discussões que pudessem conduzir a colaborações mais efetivas dos pesquisadores do Estado de São Paulo. Ocorreu, em 2007, na Faculdade de Educação da USP, sendo apresentados 79 trabalhos como painéis e, 24, em 6 sessões orais. Em 2017, está em sua décima edição e ocorrerá no Instituto Federal de São Paulo (Sertãozinho).

Nos últimos anos, também tivemos a criação do Congresso Paranaense de Educação Química (CPEQUI) que fará, em 2017, sua quinta edição. Foi criado em 2009 e acontece com uma periodicidade bienal. A média de participantes é próxima de 400 inscritos, com ápice em 600 na quarta edição. O número de trabalhos apresentados nos últimos eventos tem ficado em torno de $200 .{ }^{4} \mathrm{E}$, em Minas Gerais, ocorre, atualmente, o Simpósio Mineiro de Educação Química, que este ano estará em sua quarta edição e vem acontecendo bienalmente desde 2011, em substituição ao Encontro Mineiro de Ensino de Química, que teve sua última edição em 2003. A média de participantes vem sendo de aproximadamente 300 participantes, com ápice de 400 no III SMEQ. ${ }^{5}$

Há ainda o ECODEQ, Encontro Centro-Oeste de Debates em Ensino de Química, que foi criado em 1989 e era realizado bienalmente. Tinha como principal objetivo a discussão e a reorientação das atividades de ensino de química e ciências na região Centro-Oeste. $\mathrm{O}$ último ECODEQ aconteceu na cidade de Itumbiara, GO, em 2009 e fica premente a necessidade de que este evento seja reavivado para a solidificação da área na região Centro-Oeste. Até 2009, a média de participantes girava em torno de 400 e os trabalhos na forma de resumos, próximos a 100.

Em 2017, ocorre também o Encontro da Rede Rio de Ensino de Química, que é uma iniciativa das universidades do estado do Rio de Janeiro no sentido de congregar os pesquisadores em educação química das universidades participantes. Obviamente, pode ser que existam outros eventos não listados aqui, seja de caráter regional, local ou nacional, não sendo possível abarcar a todos em um país continental como o nosso.

Deste breve histórico, nota-se que houve um aumento importante de eventos regionais o que tem relação imediata com o aumento de pessoas que optam por trabalhar ou pesquisar sobre o Ensino de Química em várias regiões do país. A regionalização implica em descentralização, o que é importante para aqueles sujeitos que estão começando a trilhar os caminhos da pesquisa em Ensino, fazendo com que eles possam ter contato com as produções que ocorrem em nível nacional, sem a necessidade de grandes deslocamentos, que muitas vezes são bastante onerosos para uma parte considerável dos alunos dos cursos de Licenciatura em Química no Brasil. Nesse aspecto, reforçamos a importância do Programa Institucional de Bolsas de Iniciação a Docência (PIBID) que permitiu que muitos licenciandos se fixassem nos cursos, participando de eventos. Vários desses ex-bolsistas encontram-se nos programas de pós-graduação, contribuindo para a pesquisa na área. Outro aspecto importante nesses eventos, é que, mesmo tendo o alcance regional necessário para a inclusão, todos eles têm recebido inscrições de diversos outros estados do Brasil, mostrando a pujança e a necessidade de mais eventos congregadores.

Além dos eventos que promovem a interação entre os diversos sujeitos que compõem a área de Ensino de Química no país, as revistas voltadas à publicação dos resultados de pesquisas em ensino têm sido importantes veículos de divulgação e socialização dos trabalhos desenvolvidos nos diferentes grupos dispersos pelo País. Nos últimos 
anos, além da Revista Química Nova na Escola e Química Nova, com seu espaço para publicação de pesquisas voltadas para o Ensino de Química, foram criados outros periódicos que têm contribuído de maneira efetiva para os debates que permeiam os espaços formativos de educadores químicos no Brasil.

\section{REVISTAS EM ENSINO DE QUÍMICA}

A DED foi de fato pioneira quando da criação e desenvolvimento da Revista Química Nova na Escola, no ano de 1995. Até o ano de 2001, foram publicados 14 volumes únicos da revista, com dois números por ano, um por semestre, totalizando 177 artigos científicos. $^{1}$ Entre 2002 e 2008, a QNESC continuou sendo publicada na forma de um volume para cada exemplar publicado. O último exemplar de 2008 correspondia ao volume 30 , sempre seguindo a periodicidade de 2 números por ano. A partir de 2009, a revista mantém os volumes, mas passa a ter também números/fascículos. Ou seja, se antes de 2009 cada exemplar de QNESC era um volume único, de 2009 até o presente momento, cada volume corresponde a um ano. Cada volume corresponde a 4 números da revista, os quais são publicados trimestralmente. Como exemplo, o volume 38, corresponde ao ano de 2016 com 4 números diferentes.

Essa mudança tinha como objetivo ampliar o acesso à revista $\mathrm{e}$ melhorar a qualidade das publicações, iniciando também uma nova forma de referenciar os artigos publicados, atendendo a requisitos necessários para a indexação de Química Nova na Escola em outros sistemas, ${ }^{6}$ o que levaria à melhoria de sua qualificação no sistema Qualis Capes. De início, sua proposta era a de subsidiar o trabalho, a formação e a atualização de professores e professoras, propondo-se a se constituir em um espaço de educadores, que proporcionasse debates e reflexões sobre os processos de ensino e aprendizagem no Ensino de Química. ${ }^{7}$ Hoje, caracteriza-se como uma revista que, além dos objetivos descritos, passa a ser, também, um veículo importante para a publicação dos trabalhos desenvolvidos em nível de mestrado e doutorado em educação em química no Brasil.

O desafio, agora, é manter o número de artigos em um momento de crise nacional, no qual as revistas ligadas a sociedades científicas não são mais subsidiadas pelo governo federal. Nesse sentido, Química Nova na Escola, a partir de Setembro de 2016, passou a cobrar para que artigos aceitos para publicação possam ser publicados na revista. A ideia é que os autores possam cobrir parte dos custos da publicação. A diretoria da SBQ afirma que continua cobrindo grande parte dos custos da revista. A Divisão de Ensino da SBQ se posicionou contra essa determinação da diretoria da Sociedade Brasileira de Química, tentando propor novos caminhos ou alternativas. Tal aspecto gerou diferenciação de taxas para submissão de trabalhos por parte do professor do Ensino Médio, mas, mesmo assim, tal cobrança gerou grande insatisfação entre a comunidade de educadores químicos, que poderá redundar na migração de manuscritos para outras revistas.

A partir do crescimento da Divisão de Ensino e, consequentemente, da comunidade de educadores químicos, a área tem grande diversificação e passa a contar com novas revistas que também publicam artigos nessa área.

Em 2006, houve a criação da Revista Brasileira de Ensino de Química (ReBEQ) pela editora Átomo e Alínea. Sua periodicidade é semestral e, atualmente, encontra-se no volume 11 (2016), com dois números/fascículos por volume. Seu objetivo é o de difundir o conhecimento, democratizando pesquisas que quase sempre permanecem pouco divulgadas nas universidades, possibilitando o intercâmbio de ideias entre os vários atores envolvidos com a pesquisa sobre os processos de ensino e aprendizagem e sua prática. ${ }^{8}$ Geralmente, as sessões da revista são distribuídas entre artigos, relatos de experiência, história da química, química verde e resenhas. A revista tem livre acesso para leitura de todos os seus artigos, por meio da plataforma digital ISSUU, no entanto, não é possível imprimir a revista ou os artigos ou armazená-los em pastas no computador. Tanto os exemplares completos como as separatas do artigo podem ser comprados na própria página da revista.

Mais recentemente, destacamos a criação da REDEQUIM, Revista de Debates em Ensino de Química, criada em 2015, atualmente em seu terceiro ano de funcionamento, com um total de 46 artigos. Seu último número é o volume 2, número 2, de 2016. Seu escopo é a publicação de trabalhos relacionados ao ensino de Química e áreas afins. É composta pelas seções: Teoria em Foco, Artigos de Pesquisa, Resenhas de Livros, Resumos de Dissertação e Teses e cobertura de eventos científicos. ${ }^{9}$

Temos, também, a Revista Vivências em Educação Química, de periodicidade semestral, em seu segundo volume e números em 2016. A Reveq publica textos, dando visibilidade aos trabalhos dos pesquisadores e professores do Ensino Fundamental, Médio e Superior. É uma revista específica da área que contempla pesquisa de natureza teórica, empírica e experimental no formato de artigos, ensaios, relatos de resumos estendidos, traduções e resenhas. ${ }^{10}$ Finalmente, com seu primeiro número previsto para o primeiro semestre de 2017, temos a Educação Química em Punto de Vista, que é uma publicação da Rede Latino-Americana de Pesquisa em Educação Química - ReLAPEQ, criada em 2014. A missão da revista é difundir trabalhos relacionados à educação química produzidos em diferentes países e contextos educacionais, conferindo um caráter de internacionalização à revista e, ao mesmo tempo, compreendendo diferentes realidades tais como: Ensino Fundamental, Ensino Médio, Ensino Superior, formação de professores e educação em espaços não-formais. ${ }^{11}$

Há, ainda, trabalhos concernentes ao Ensino de Química, tanto em Química Nova (QN), quanto na Revista Virtual de Química (RVq), ambas ligadas à SBQ que, embora não tenham como foco a publicação específica da área, contribuem para a socialização de pesquisas desenvolvidas no âmbito da área de Educação Química. A QN, desde sua criação em 1978, tem uma seção dedicada aos temas de educação em Química e, nesta seção, foram e continuam sendo publicados importantes artigos que sustentaram discussões entre pesquisadores da área e que subsidiaram diálogos sobre a formação de professores ao longo das últimas 4 décadas. ${ }^{1}$ Até 2002 foram cerca de 150 artigos. No intervalo 2002-2016 foram aproximadamente 400 artigos, considerando-se sempre de 2 a 4 artigos por número publicado. Em relação à $\mathrm{RVq}$, há a perspectiva de publicação de artigos que se refiram a aspectos relacionados à educação em diversos níveis de formação dos profissionais da área e, nesse viés, já foram publicados alguns textos que discutem questões formativas das Licenciaturas em Química.

Na Tabela 2, estão apresentados os conceitos Qualis obtidos pelas revistas sobre educação em Química existentes no Brasil e, também, de revistas de Química que publicam trabalhos sobre essa temática, demonstrando o esforço da comunidade em busca da melhoria dos trabalhos e de seu alcance. Nessa tabela, apresentamos somente as revistas qualificadas em alguns dos comitês do Qualis/CAPES, a saber, ENSINO, EDUCAÇÃO, QUÍMICA e INTERDISCIPLINAR, salientando que algumas das revistas listadas constam em outros comitês.

Pressupõe-se, pelo aumento do número de periódicos voltados a abordagens sobre o ensino e a pesquisas na área de Educação Química surgidos nos últimos anos e por sua diversificação, que houve também um aumento do número de pessoas envolvidas com essa área. Tal aumento decorre dos diversos fatores já citados anteriormente, como mais eventos para discutir questões de interesse e maior número de Programas de Pós-graduação. No entanto, um fator que impulsionou sobremaneira a ampliação da área foi o aumento de cursos de Licenciatura em Química no País, assunto do qual trataremos a seguir. 
Tabela 2. Qualis CAPES - Revistas em Educação em Química do Brasil

\begin{tabular}{lcccc}
\hline Revista & \multicolumn{3}{c}{ QUALIS } & \\
\cline { 2 - 5 } & Ensino & Educação* & Química & Interdisciplinar \\
\hline Química Nova na Escola & B1 & B2 & B4 & B2 \\
Revista Brasileira de Ensino de Química & B1 & - & C & B2 \\
Revista de Debates em Ensino de Química & B4 & - & B2 & C \\
Química Nova & B3 & - & B3 & B2 \\
Revista Virtual de Química & B3 & B5 & B4 \\
Periódico Tchê Química & B5 & - & B & \\
\hline
\end{tabular}

* O Qualis Educação utilizado foi o de 2014.

\section{EVOLUÇÃO DO NÚMERO DE CURSOS DE LICENCIATURA EM QUÍMICA E DE PESQUISADORES EM EDUCAÇÃO QUÍMICA NO BRASIL}

Em 2002, quando foi publicado o artigo de Scnetzler, ${ }^{1}$ a revisão apresentada por ela mostrou que, na época, havia 77 mestres e 32 doutores com trabalhos de pesquisa na área de Ensino de Química. Do recorte apresentado para cá, houve uma evolução quantitativa. Uma revisão mais recente, ${ }^{12}$ de 2013 , a partir dos contatos de pesquisadores cadastrados no sistema de banco de dados da Divisão de Ensino da SBQ, mostra que existiam cerca de 140 mestres e 113 doutores na área de Educação em Química. Salientamos que, do total de mestres, 52 encontravam-se em processo de doutoramento. A partir desses dados, pode-se inferir que, no País, atualmente, haja cerca de 200 doutores na área.

É importante ressaltar que esse número pode ser bem maior, pois nem todos os pesquisadores da área se vinculam à SBQ, considerando que há outras instâncias de interlocução como a Associação Brasileira de Pesquisa em Educação em Ciências (ABRAPEC) e os ENEQs. Para se ter uma estimativa, na última reunião promovida pela ABRAPEC, o Encontro Nacional de Pesquisadores em Ciências (ENPEC), em 2015, houve a submissão de cerca de 1700 trabalhos, dentre os quais se encontravam os da área de Ensino de Química. No último ENEQ, em 2016, houve cerca de 2300 inscrições, entre pesquisadores, professores e licenciandos.

A maioria desses profissionais é formada em Instituições Públicas de Ensino Superior, pois o curso de Química é um curso caro, em que os insumos não são permanentes, devido às disciplinas experimentais, em que há necessidade de reagentes e técnicos de laboratório. Além disso, a demanda por cursos de Licenciatura é mais baixa do que a de cursos como o de Farmácia ou de Biomédicas, por exemplo. Essas características fazem com que os cursos dessa área não sejam economicamente interessantes para as mantenedoras privadas.

$\mathrm{O}$ aumento de profissionais e estudantes nas Licenciaturas em Química resulta de uma situação posta a partir da promulgação da Lei de Diretrizes e Bases da Educação Nacional, Lei 9394/96, ${ }^{13}$ que estabeleceu como normativa que os professores da Educação Básica deveriam ser licenciados em suas respectivas áreas de atuação (BRASIL, 1996). A partir de tal direcionamento, houve o aumento do número de cursos de Licenciatura em Química no Brasil, considerando-se tanto a precariedade da oferta dessa formação no País como o déficit de professores para essa área.

Ao invés de se apresentar uma retomada histórica que demandaria um recorte específico sobre o tema, apresenta-se, aqui, uma comparação entre o ano de 1965, em que havia apenas 13 cursos de formação de professores de Química no País ${ }^{14}$ e o período atual, em que há cerca de 380 cursos de Licenciatura em Química presenciais em atividade no Brasil, de acordo com dados do e-mec. ${ }^{15}$
Ações governamentais como o Programa de Reestruturação e Expansão das Universidades Federais (REUNI) e o Programa de Expansão da Rede Federal de Educação Profissional e Tecnológica contribuíram para o aumento do número de cursos. No caso específico dos cursos de Licenciatura em Química nos Institutos Federais (IF), Franco e Pires ${ }^{16}$ evidenciaram que, em 2008, havia 15 desses cursos sendo ofertados pelos IFs. Já em levantamento feito por Alves ${ }^{17}$, existem 85 cursos de Licenciatura em Química nos IFs. Tal aumento considerável, nos últimos dez anos, traz consigo perspectivas positivas em termos de maior número de profissionais atuantes na área de formação de professores de Química. No entanto, concordamos com as colocações de Maldaner, ${ }^{18}$ que argumenta sobre a falta de formadores de professores com preparo adequado no sentido de estruturar, em termos de pesquisa e ensino, os cursos para a formação de educadores químicos.

Esse é um dos problemas mais evidentes, pois embora tenha havido um aumento do número de Licenciaturas em Química no País, os cursos de mestrado e doutorado específicos para a formação na área de Ensino de Química ainda não atendem, em termos de quantidade, as demandas da área. Nesse aspecto, há dois problemas que precisam ser pontuados. Pelo fato de praticamente não existirem cursos de mestrado e doutorado em Ensino de Química, as pesquisas são desenvolvidas em outros espaços. Há linhas de pesquisa em Ensino de Química em programas dentro dos Institutos ou Departamentos de Química e há linhas de pesquisa em programas de algumas Faculdades de Educação. Em ambos os casos, há dificuldades de estabelecimento de diálogo no contexto epistemológico, pois, nos Institutos de Química, as disciplinas que serão exigidas dos pós-graduandos não os levam a se aprofundarem as questões mais específicas associadas à pesquisa na área, além de seu convívio diário não favorecer as discussões atinentes a esse campo de pesquisa.

Nesse aspecto, os periódicos em que se publicam os artigos sobre Ensino de Química/Ciências, são melhores qualificados quando submetidos ao Qualis/Capes do comitê de ensino. Esses mesmos periódicos, quando analisados ou classificados no comitê da Química, têm, tipicamente, menor conceito/classificação do que as revistas da área técnica. Para exemplificar, a revista Ciência e Educação é qualificada como A1, no último Qualis Ensino. No entanto, é qualificada na Química como B5. Tal aspecto faz com que pesquisadores da área de ensino de química que orientam trabalhos em mestrados/ doutorados em Química, tenham seus trabalhos desvalorizados em termos conceituais, ou são obrigados a restringir suas publicações em Química Nova ou Journal Chemical Education, qualificados na Química como B2. Essa questão pode ter um efeito negativo sobre a qualificação da pesquisa desenvolvida nessa linha, se não houver um claro entendimento dessas questões no Departamento/Instituto de Química em que se desenvolve a linha de pesquisa em Ensino de Ciências. Esse é um aspecto que deve ser considerado e analisado nos vários comitês existentes na CAPES, pois, provavelmente não 
acontece somente no âmbito do Ensino de Química/Química.

Um terceiro locus para o desenvolvimento das pesquisas e da formação continuada para os docentes da área de Ensino de Química, no qual existe um maior entrelaçamento entre as interfaces da Educação e da Química, são os programas de pós-graduação em Educação/ Ensino em Ciências e Matemática. No entanto, esses programas ainda existem em pequena quantidade, considerando-se a quantidade de cursos de Licenciatura na área de Ciências em geral. Para termos uma ideia, nas regiões Norte e Nordeste, existem apenas quatro programas de pós-graduação, nível Doutorado, de Educação em Ciências e Matemática que são ofertados pela UFPA, UNB, UFG e UFMT.

Dentre os programas de pós-graduação em ensino de ciências, temos aqueles que são profissionalizantes e que também vem formando pesquisadores e docentes na área de química. Nessa especificidade, o governo federal lançou nos últimos anos, programas de pós-graduação profissionalizantes em rede, específicos para professores do ensino médio em diferentes áreas do conhecimento. O debate em torno desse formato de pós- graduação se refere às perspectivas formativas que não necessariamente focam em questões do conhecimento pedagógico específico. Quando da criação do Programa de Mestrado Profissional em Química em Rede Nacional (PROFQUI), a comunidade de educadores químicos participou de alguns debates, não havendo unanimidade em relação a participação e atuação de pesquisadores da área nesse programa. No entanto, a criação do programa foi conduzida e efetivada pela diretoria da SBQ, sob coordenação geral do Instituto de Química da Universidade Federal do Rio de Janeiro. O primeiro edital foi publicado no ano de 2017.

Nesse contexto, um dos desafios do momento atual refere-se à ampliação, com qualidade, de cursos de mestrado e doutorado para que a formação pós-graduada dos Licenciados em Química possa ser efetivada e para que a área de Ensino de Química tenha, também, um número de doutores que se equipare ao de outras áreas de formação da Química.

Nesse sentido, a comunidade de educadores químicos precisa estar atenta à necessidade de que os concursos realizados nas IES considerem as especificidades para o ensino e para pesquisa no âmbito da formação de professores de Química, pois há que se ter cautela com relação a pesquisadores com formações em outras áreas de pesquisa da Química que possam vir a ocupar espaços formativos cuja natureza epistemológica apresenta um viés próprio, sem o devido conhecimento do campo e sem interesse em vir a pesquisar na área de Ensino.

Em termos de investigações em Ensino de Química/Ciências, nas últimas décadas tem-se destacado trabalhos referentes às seguintes temáticas: identificação de concepções alternativas de alunos; resolução de problemas; investigação didática das práticas de laboratório e de campo, validação e avaliação de materiais didáticos; relações ciência, tecnologia e sociedade e o papel do meio; linguagem e comunicação em sala de aula; modelos e analogias; concepções epistemológicas de professores; formação de professores; história da ciência; questões curriculares e de avaliação; o papel das novas tecnologias de comunicação e questões axiológicas que focam diferenças de gênero, diversidade cultural e problemas de poder/políticos. ${ }^{19}$ Importante notar que tais temáticas não são fundamentalmente diferentes daquelas citadas por Schnetzler ${ }^{1}$.

Nas perspectivas atuais as publicações ainda convergem para as temáticas citadas, no entanto, surgem novos contornos investigativos, tais como Ensino de Química e suas relações com: Direitos Humanos; Educação Inclusiva; Questões Étnico-Raciais; Semiótica; Ludicidade, entre outros. Salientamos que esses contornos alinham-se aos direcionamentos legais postos para a formação de professores nas últimas duas décadas. Esses aspectos apresentam dificuldades nos entrelaces com a abordagem dos conteúdos de Química e todas essas temáticas exigem profissionais que tenham formação específica para trabalhá-las, no contexto formativo de professores de química, tanto no ensino quanto na pesquisa.

\section{CONSIDERAÇÕES FINAIS}

No contexto apresentado, notamos que a SBQ, por meio da DED, configurou-se como importante locus da estruturação da área de pesquisa voltada ao Ensino de Química no cenário nacional. A DED foi o primeiro espaço agregador dos pesquisadores e possibilitou tessituras e diálogos entre professores de diversas instituições, promovendo os necessários entrelaces para o reconhecimento dos educadores químicos brasileiros como representantes de uma área legítima da pesquisa em Química do País. Com esse crescimento, outros espaços precisam ir se constituindo, considerando-se a gama de pessoas e grupos que passaram a fazer parte desse universo, mas tanto a DED quanto a QNEsc fazem parte da história da consolidação e desenvolvimento desse campo de pesquisa no Brasil.

Tendo em vista o processo de legitimação da área de pesquisa em Ensino de Química no Brasil, nos últimos quarenta anos, evidenciado por alguns aspectos, tais como: mudanças na legislação, criação de eventos e revistas específicas da área e aumento dos cursos de Licenciatura, há desafios que se configuram na atualidade que necessitam ser pensados em conjunto pelo coletivo da área. Entre tais desafios, as questões políticas são as que mais se colocam como problemáticas no sentido de pôr em risco todo um corpo de conhecimentos construído ao longo das últimas décadas. Essas questões políticas envolvem o modelo de formação docente a ser implementado nos próximos anos, a necessidade imperiosa de valorização da profissão docente e a proposta de formação na Educação Básica. São estes os principais elementos, pois, a partir das diretrizes que se imponham para esses aspectos, serão trilhados os caminhos para o Ensino de Química e para a educação em geral. Caminhos esses que podem tanto reverberar em novas perspectivas de investigações e ações ou em necessários recomeços e reestruturações, pois muito do que foi conquistado poderá ter sido perdido.

A DED se mantém atenta a todos esses percalços e, em conjunto com os educadores químicos do País, compromete-se na busca de caminhos e diálogos que resultem em reconhecimento e espaço para uma área que se construiu no entrelace com a história do ensino e da Química como um novo campo de conhecimento que tem muito a contribuir para a formação científica brasileira.

\section{AGRADECIMENTOS}

Uma série de dados presentes neste trabalho só foi possível graças às valiosas contribuições dos colegas: Amadeu Bego (UNESP), Bruno Leite (UFRPE), Camila Silveira da Silva (UFPR), José Guilherme da Silva Lopes (UFJF), José Luis Silva (UFBA), Maisa Helena Altarugio (UFABC), Maria Inês Petrucci Rosa (UNICAMP), Ricardo Gauche (UnB) e Tathiane Milaré (UFSCar), aos quais agradecemos imensamente pela disponibilidade.

\section{REFERÊNCIAS}

1. Schnetzler, R. P.; Quim. Nova 2002, 25, Supl. 1, 14.

2. Silva, J. L. B; Moradillo, E. F.; Oki, M. C. M.; Cunha, M. B. M.; Bejarano, M. R.; Lobo, S. F.; Viana, H. E.; Cortes Jr, L. P.; Penha, A. F.; Machado, A. L.; Moreira, B. C. T.; Sá, C. S. S.; Souza, R. A.; Varjão, T. A.; Neta, M. L. C.; Carvalho, M. F. A.; Villa, S. M. S.; Massena, E. P.; Santos, I. M.; Sá, L. P.; Guzzi Filho, N. J.; Ribeiro, A. T.; Santos, B. F.; Cerqueira, S. S.; Fadigas, J. C.; Pimentel, S. C.; Em Ensino de Química: visões e reflexões; Mol, G., ed.; Ijuí, RS: Editora Unijuí, 2012, cap 4. 
3. Viveiro, A. A.; Bego, A. M.; Silva, C. S.; Em O Ensino de Ciências no Contexto da Educação Inclusiva: Diferentes matizes de um mesmo desafio; Viveiro, A. A.; Bego, A. M., eds., Jundiaí: Paco Editorial, 2015, cap 1.

4. Congresso Paranaense de Educação Química. http://inscricao4cpequi. wixsite.com/4cpequi , acesso em 25/03/2017.

5. Simpósio Mineiro de Educação Química. www.smeq.com.br, acesso em 25/03/2017.

6. Giordan, M.; Maldaner, O. A.; Santos, W. L. P.; Quim. Nova Esc. 2009, 31,1 .

7. Beltran, N. O.; Quim. Nova Esc. 1995, 1, 1.

8. Revista Brasileira de Ensino de Química. www.rebeq.revistascientificas. com.br, acesso em 25/03/2017.

9. Revista Debates em Ensino de Química. www.redequim.com.br, acesso em 25/03/2017.

10. Revista Vivências em Educação Química. http://periodicos.piodecimo. edu.br/online/index.php/reveq, acesso em 25/03/2017.
11. Revista Educação Química en Punto de Vista. http://www.seer.ufal.br/ index.php/eqpv/index, acesso em 25/03/2017.

12. Mol, G. S.; Silva, R. M. G.; Souza, F. N.; Indagatio Didactica 2013, 5, 179.

13. Brasil, Lei de Diretrizes e Bases da Educação Nacional, no. 9394/96.

14. Mesquita, N. A. S.; Soares, M. H. F. B.; Quim. Nova 2011, 34, 165.

15. E-mec. Disponível em: http://emec.mec.gov.br/, acesso em 25/03/2017.

16. Franco, R. Z.; Pires, L. L. A.; Anais do XVIII Simpósio Nacional de Ensino de Física, Vitória, Brasil, 2009.

17. Alves, D. A.; Dissertação de Mestrado, Universidade Federal de Goiás, Brasil, 2016.

18. Maldaner, O. A.; Em Educação Química no Brasil: memórias, políticas e tendências; Rosa, M. I. P.; Rossi, A. V., eds, Ijuí, RS: Unijuí, 2008, cap. 1.

19. Cachapuz. A.; Gil-Perez, D.; Carvalho, A. M. P.; Praia, J.; Vilches; A.; A Necessária Renovação do Ensino das Ciências. São Paulo: Cortez Editora, 2005. 